\title{
Effect of Red Mud (RM) Reinforcement on Physio-Chemical Characteristics of Ordinary Portland Slag Cement (OPSC) Mortar
}

\author{
Harekrushna Sutar ${ }^{1,2,3 *}$, Rabiranjan Murmu1, Debashis Roy ${ }^{2}$, Subash Chandra Mishra ${ }^{3}$, \\ Asmita Mishra ${ }^{1}$ \\ ${ }^{1}$ Chemical Engineering Department, Indira Gandhi Institute of Technology, Sarang, India \\ ${ }^{2}$ Chemical Engineering Department, Jadavpur University, Kolkata, India \\ ${ }^{3}$ Metallurgical and Materials Engineering Department, National Institute of Technology, Rourkela, India \\ Email: "h.k.sutar@gmail.com
}

Received 30 June 2016; accepted 24 July 2016; published 28 July 2016

Copyright (C) 2016 by authors and Scientific Research Publishing Inc.

This work is licensed under the Creative Commons Attribution International License (CC BY).

http://creativecommons.org/licenses/by/4.0/

(c) (i) Open Access

\section{Abstract}

The investigation focuses on evaluating the effect of varying \% of Red Mud (RM) reinforcement with Ordinary Portland Slag Cement (OPSC). Characterisation is done by adding $10 \%, 20 \%, 30 \%, 40 \%$ and $50 \%$ of RM by weight to OPSC. RM + OPSC composite mortars are made in an $8.5 \times 5 \times 4 \mathrm{~cm}^{3} \mathrm{cast}^{\circ}$ iron mould with external vibration keeping water-binder ratio 0.4 by weight. The mortars are cured in water for 28 days and their physio-chemical characteristics are investigated. Mortar performances like compressive strength, hardness, XRD, FTIR, SEM are diagnosed. The composite mortars cementing properties are compared with original OPSC. The result reveals the augmentation of RM with OPSC increases the hydration capacity of OPSC with improved compressive strength. The experimental optimization shows a maximum value up to $10 \%-20 \%$ OPSC can be replaced by RM as filling material.

\section{Keywords}

Red Mud, Cement, Compressive Strength, XRD, FTIR, SEM

\section{Introduction}

For last several years it is observed that ground granulated blast furnace slag has been widely used as a partial replacement for Ordinary Portland Cement (OPC) for concrete manufacturing. Slag as partial replacement in OPC in term uses the waste produced in steel industry, and hence reduces the carbon dioxide emissions produced during

${ }^{*}$ Corresponding author.

How to cite this paper: Sutar, H., Murmu, R., Roy, D., Mishra, S.C. and Mishra, A. (2016) Effect of Red Mud (RM) Reinforcement on Physio-Chemical Characteristics of Ordinary Portland Slag Cement (OPSC) Mortar. Advances in Materials Physics and Chemistry, 6, 231-238. http://dx.doi.org/10.4236/ampc.2016.68023 
cement making [1]. In addition to that, partial replacement of OPC by slag enhances certain physiological properties like reducing heat of hydration and corrosion risk [2]. Many constituents are responsible for hydration of ordinary Portland cement paste. The calcium silicate hydrate (C-S-H) phase is the primary product of OPC hydration [3]. The amount of combined water (bound) presented in OPC after hydration is dependent on phase composition of the original cement and on the degree of hydration [4]. Usually similar hydration products are found when OPC is partially replaced by slag [5]. But the amount of $\mathrm{Ca}(\mathrm{OH})_{2}$ in OPC/slag composite is higher than that in OPC pastes.

But it is worthy to discuss that ordinary Portland blast furnace slag cement (OPSC) is a mixture of ordinary Portland cement and not more than 65 weight \% of granulated slag. It is generally seen that the hardening rate of slag cement is somewhat lower than OPC for the first 28 days curing, but then increases and after 12 months the compressive strength merges with OPC. As blast furnace slag is hydraulically weak, it has glassy structure and high alkaline medium is required to neutralize the silicate-aluminate network [6]. The idea of adding foreign materials like rice husk, silica fumes and zinc nanoparticles to OPSC is widely practised in order to reduce cost, conserve energy and protect environment. Literature reveals characterisation of Portland-blast furnace slag cement containing cement kiln dust and active silica [7]. An investigation on a variety of slag, fly ash and cement dust in the performance of industrial by products is reported [8]. Mechanisms and kinetic study of slag hydration in hydrated slag cement are available [9] [10].

The outline for red mud reinforcement in OPC or OPSC is not revealed till. The red mud is generated as a byproduct (waste) material in alumina production during bauxite purification by Bayer's process. A comprehensive outline of red mud applications is available [11]. The objective of this work is to evaluate the effect of partial substitution of OPSC by RM on its physio-chemical characteristic of the hardened composite pastes.

\section{Experimental}

\subsection{Raw Materials}

At incipient red mud was collected as wet powder form from NALCO, Damonjodi, India. The as received power was dried under sunlight for 10 days to get moisture content up to $2 \%$ by weight. The red mud powder was ball milled to a specific particle size below $50 \mu \mathrm{m}$ diameter. The composition of red mud used can be collected from [12]. The OPSC was procured from Sarang market as Konark cement, manufactured by Odisha cement limited, Rajgangpur, India.

\subsection{Casting}

The red mud and cement mixture was prepared separately by varying the weight $\%$ of red mud as $10,20,30,40$ and 50. Each mixture was thoroughly blended using an in house V-shaped blender, in order to get a uniform composite powder. Thereafter each composite powder was stirred with distilled water using a mixture (Guangzhou Xuzhong Machinery Company Limited). The water-binder ratio is maintained at a value of 0.4 . The paste is poured into the cast iron mould to fill the entire volume. Casting was done by using a cast iron mould of size $8.5 \times 5 \times 4$ $\mathrm{cm}^{3}$. Captured image of the die used for casting is shown in Figure 1. Then the die was mechanically vibrated

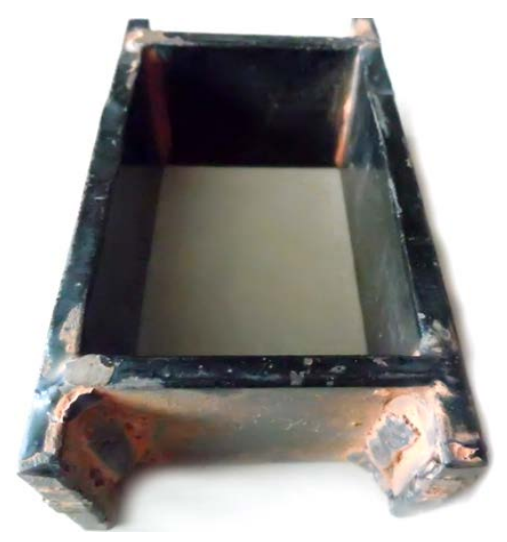

Figure 1. Snapshot of the matrix. 
using external vibrator to achieve ultimate compaction of the paste. The die was removed immediately and composite bricks are allowed to harden for 2 days and then went for curing in normal water for 28 days at atmospheric condition.

\section{Results and Discussion}

\subsection{Compressive Strength and Hardness}

Compressive strength is the most vital property to characterise the cement. The mortars were cut to cylindrical pieces having height to diameter ratio of 5.6. The specimen was compressed between the planets of the compression testing machine (Instron-1195) by application of load as per ASTM C39 standard. The results are shown in Figure 2, and compared with Indian standard IS 455 - 1989 designed for PSC. As normal PSC/OPSC bear a compressive strength of $33 \mathrm{MPa}$ after 28 days of curing.

The results reveal an improved compressive strength up to $20 \%$ red mud reinforcement, might be due to improved hydration and structural properties approximating minimum air voids prevailing in the 20\% RM composite.

Hardness of the sample was determined using Vickers hardness test equipment (LHV-1000B), applying 50 gram load with 10 seconds indentation time. The results are reported in Figure 3. It is observed that hardness is extreme for $10 \%$ red mud composite mortar. It is evident that the inclusion of RM to OPSC affects the rate at which it hydrates and changing its hardening properties.

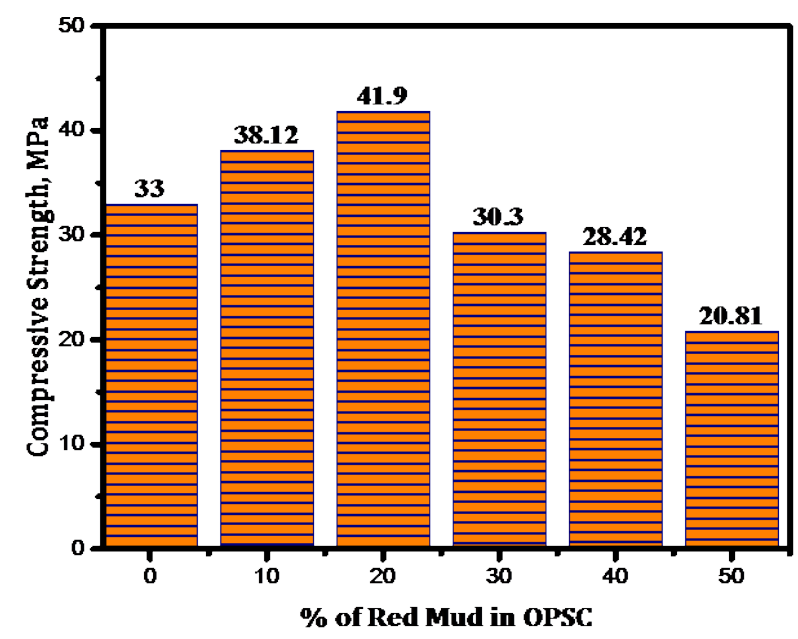

Figure 2. Variation of compressive strength with reinforcement of RM

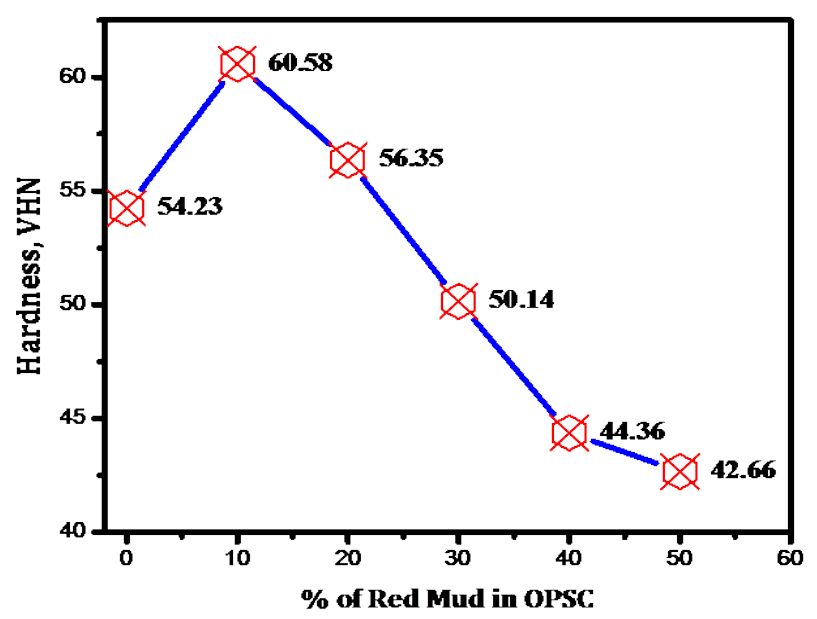

Figure 3. Hardness of OPSC and Composite mortars after 28 days curing. 


\subsection{XRD, FTIR, SEM}

Figure 4(a) shows the XRD pattern of OPSC after 28 days hydration. The XRDs were captured using a Philips $\mathrm{X}$-ray diffractometer. Emphasis is given to analyse only the phase compositions. It was seen that the primary phases OPSC builds up after 28 days hydration are Calcite $\left(\mathrm{CaCO}_{3}\right)$, Portlandite $\left(\mathrm{Ca}(\mathrm{OH})_{2}\right)$, Calcium Silicate Hydrate $(\mathrm{C}-\mathrm{S}-\mathrm{H})$ and minor phases are Larnite $\left(2 \mathrm{CaO}\right.$. $\left.\mathrm{SiO}_{2}\right)$, Calcium Aluminate $\left(3 \mathrm{CaO} . \mathrm{Al}_{2} \mathrm{O}_{3}\right)$ and Monosulphate hydrate $\left(3 \mathrm{CaO} . \mathrm{Al}_{2} \mathrm{O}_{3}\right.$. $\left.3 \mathrm{CaSO}_{4} .3 \mathrm{H}_{2} \mathrm{O}\right)$. Portlandite and Calcium silicate hydrate are formed after water hydration. But rest of the phases are also seen in OPSC powder [13]. Figure 4(b) and Figure 4(c) reveals the XRD patterns of $20 \% \mathrm{RM}+80 \%$ OPSC and $40 \% \mathrm{RM}+60 \%$ OPSC composite mortars after 28 days hydration. Two new phases are found in the composite mortars as Hematite $\left(\mathrm{Fe}_{2} \mathrm{O}_{3}\right)$ and Silicon dioxide $\left(\mathrm{SiO}_{2}\right)$, that red mud consistently poses. From the XRD analysis point of view; no new compound indicated, and there is no alternation in the phases by presence of RM particles was identified. Only revision of the relative intensities of the peaks was observed.

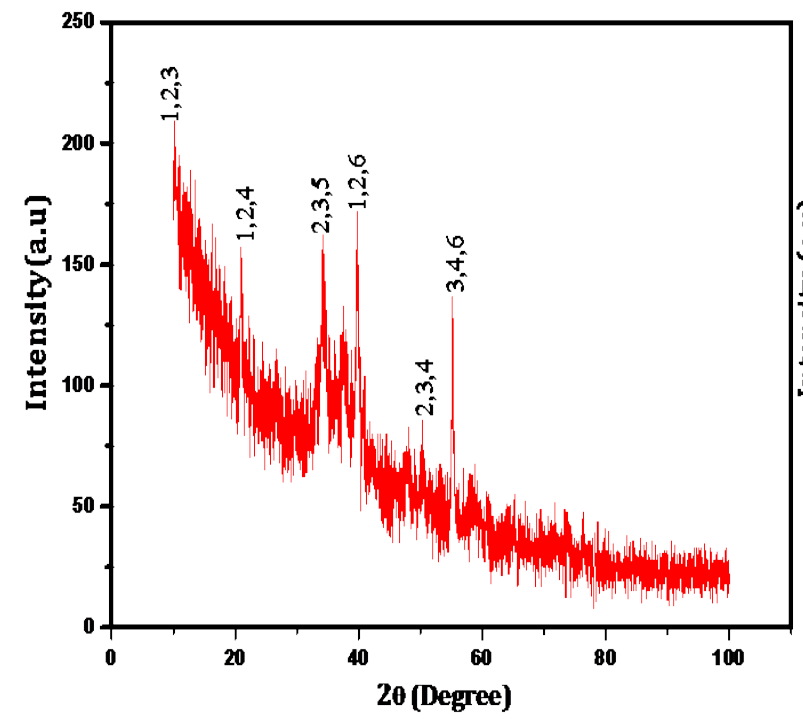

(a)

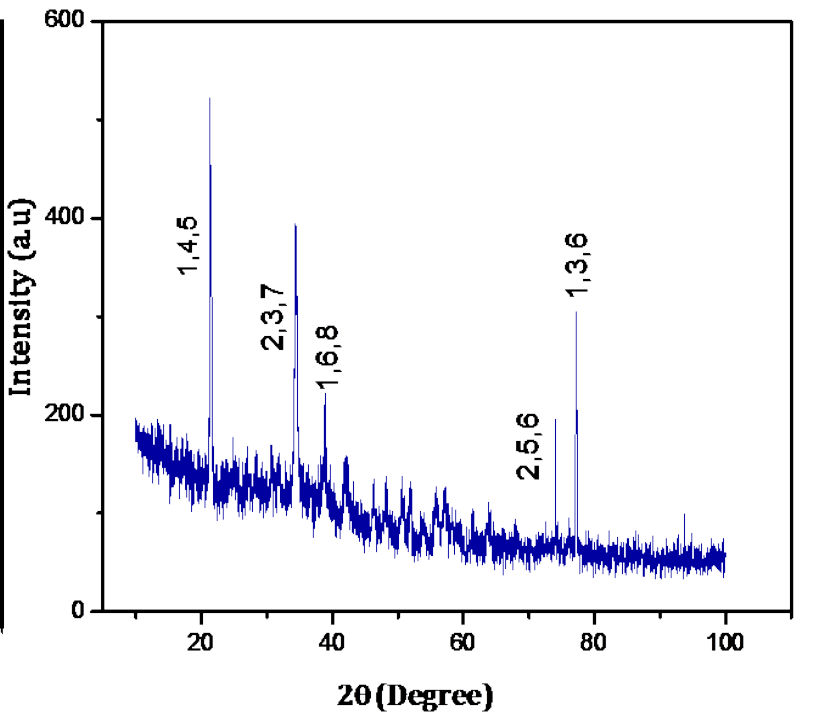

(b)

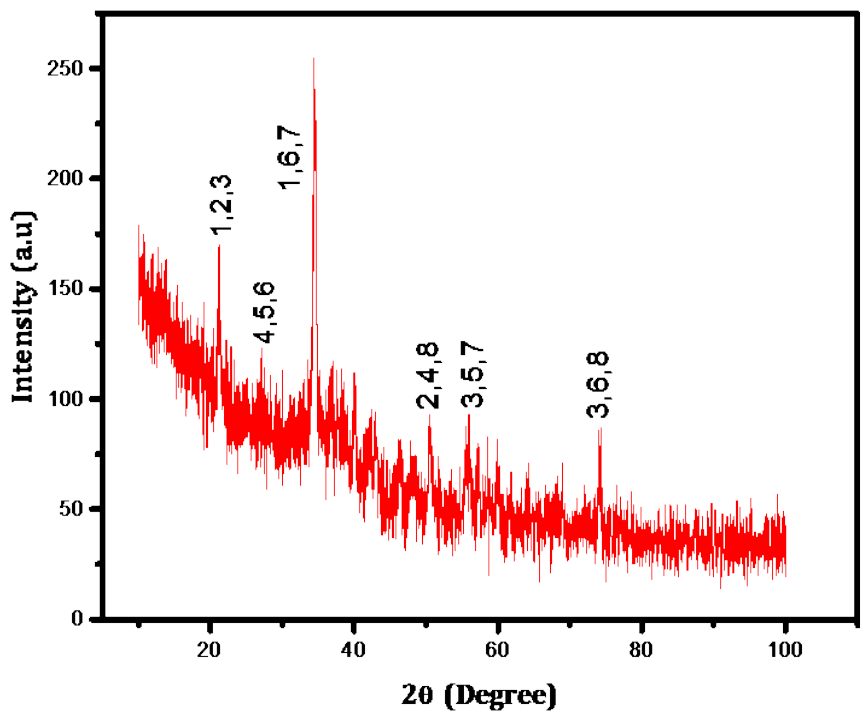

(c)

Figure 4. X-ray traces of (a) OPSC, (b) $20 \% \mathrm{RM}+80 \%$ OPSC, (c) $40 \% \mathrm{RM}+60 \%$ OPSC mortars. 1. Calcite $\mathrm{CaCO}_{3}$; 2. Portlandite $\mathrm{Ca}(\mathrm{OH})_{2}$; 3. Calcium Silicate hydrate C-S-H; 4. Larnite $2 \mathrm{CaO} . \mathrm{SiO}_{2}$; 5. Calcium Aluminate 3CaO. $\mathrm{Al}_{2} \mathrm{O}_{3}$; 6. $\mathrm{Mono-}$ sulphate hydrate $3 \mathrm{CaO} . \mathrm{Al}_{2} \mathrm{O}_{3}$. $3 \mathrm{CaSO}_{4}$. $3 \mathrm{H}_{2} \mathrm{O} ; 7$. Hematite $\mathrm{Fe}_{2} \mathrm{O}_{3} ; 8$. Silicon dioxide $\mathrm{SiO}_{2}$. 
The IR characteristics of OPSC after 28 days hydration are identified and reported in Figure 5(a) using FTIR analyser (thermo Scientific ${ }^{\mathrm{TM}}$ Nicolet $^{\mathrm{TM}}$ iS $^{\mathrm{TM}}$ 10) within the range of $500-4000 \mathrm{~cm}^{-1}$. Table 1 reports the IR bands and their corresponding functional groups. Figure 5(b) reveals the IR spectra of $20 \%$ RM $+80 \%$ OPSC composite mortar succeeded by 28 days hydration, their IR frequencies and assigned groups are dispersed in Table 2. Additional H-OH stretch (bound water) was observed for 20\% RM composite cement at 2923.76 and

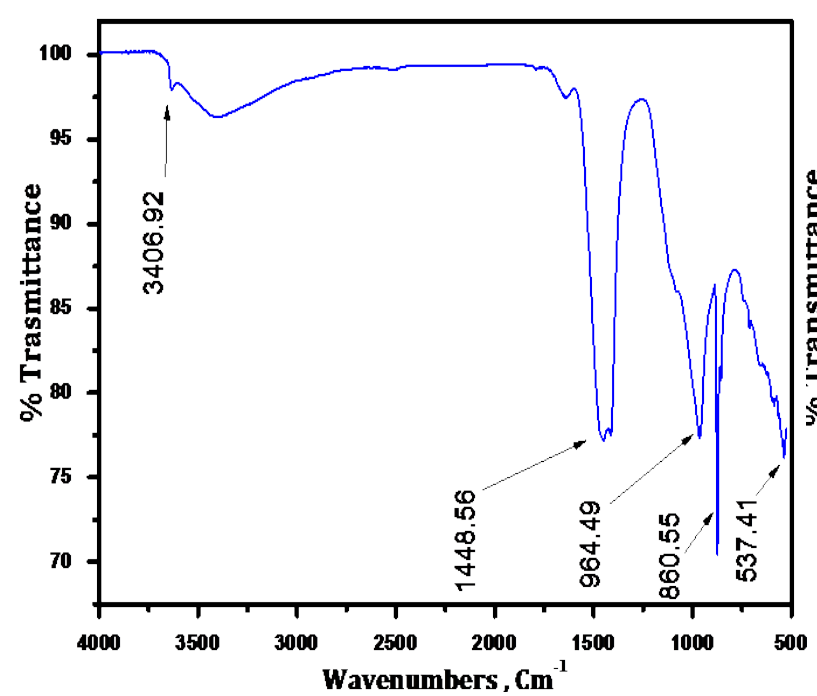

(a)

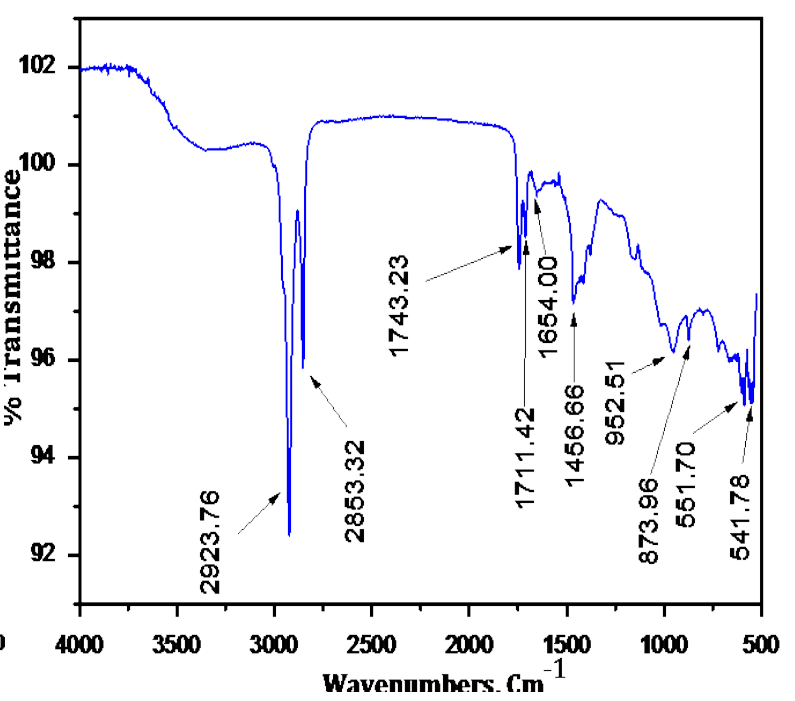

(b)

Figure 5. FTIR spectra of (a) OPSC and (b) 20\% RM + 80\% OPSC mortar.

Table 1. FTIR spectra of OPSC after 28 days hydration.

\begin{tabular}{cc}
\hline Wave band, $\mathbf{~ c m}^{\mathbf{- 1}}$ & Assigned group \\
3406.92 & (-O-H) stretch, H bonded \\
1448.56 & Carbonate CO-stretch \\
964.49 & Silicate SiO stretch \\
860.55 & Carbonate CO bend \\
537.41 & C-Br stretch \\
\hline
\end{tabular}

Table 2. IR spectra of $20 \% \mathrm{RM}+80 \%$ OPSC after 28 days hydration.

\begin{tabular}{ccc}
\hline Wave band, $\mathbf{~ c m}^{-1}$ & Assigned group \\
2923.76 & Bound water (H-OH stretch) \\
2853.32 & Bound water (H-OH stretch) \\
1743.23 & $\mathrm{CO}_{2} \mathrm{CO}$ stretch \\
1711.42 & Bound water HOH bend \\
1654.00 & Bound water HOH bend \\
1456.66 & Carbonate CO stretch \\
952.51 & Silicate SiO stretch \\
873.96 & Sulphate SO stretch \\
551.70 & C-Br stretch \\
541.78 & C-Br stretch
\end{tabular}


$1711.42 \mathrm{~cm}^{-1}$ band. This might be due to higher rate of hydration with RM reinforcement. As the process of hydration is the progressive conversion of free (liquid) water in capillary pores in to bound water during the cement hydration. So it is a good approximation that inclusion of RM (up to 20\%) to OPSC minimizes the free water and increases bulk liquid water and structural (chemically bound) water. The C-S-H gel phase is responsible to carry significant amount of free and adsorbed water in its gel pores, and holds more tightly bound water within its inter particle spaces catalysed by RM.

Morphology of composite mortars after 28 days hydration is captured using a SEM (Scanning Electron Microscope, JEOL; JSM-6480 LV). Microstructures are shown in Figure 6 and Figure 7. For 10\% RM + 90\% OPSC composite; distribution of RM particles is relatively low. Quite low numbers, small size air voids (pores) are visible. Minimum amount of air voids are observed for 10\% - 20\% RM reinforcement. Entrained air voids (porosity) are seen to be increasing for further addition of RM. The entrapped air bubbles are formed in during mixing of water-binder and play a dominant role for their effect on the strength of the concrete. More isolated and bigger globular voids (large capillary pores) are seen for 50\% RM $+50 \%$ OPSC mortar and hence lowering the effectiveness. The inclusion of RM (<20\%) might be helping for increasing the C-S-H gel formation (including its internal gel pores) and thereby increasing the strength.

\section{Conclusion}

The combined use of XRD, FTIR and Scanning electron microscopy techniques reveals the output results for reinforcing red mud in OPSC. It permits to study the hydration of OPSC with red mud, evaluating the variation of hydration rate and formation of phases if any. It is concluded that red mud inclusion in OPSC improves the hydration rate and increases the concrete strength. No chemical changes involve during hydration of the composite mortars as no new phases are identified. The IR technique innovates more bound water existence during hydration with red mud, attributing to $\mathrm{H}-\mathrm{OH}$ stretching. Thus red mud may be used for partial replacement of OPSC up to $20 \%$ by weight and can be implemented as filling material, substituting OPSC.

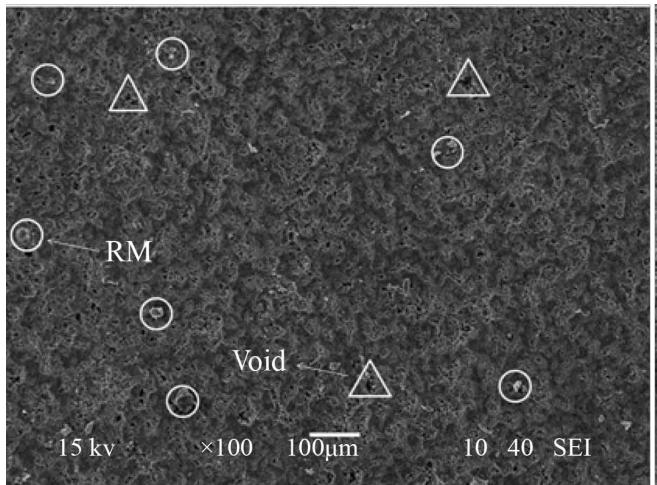

(a)

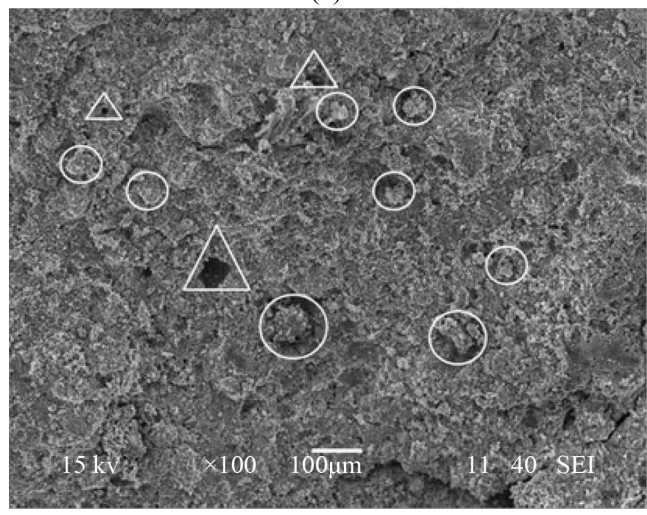

(c)

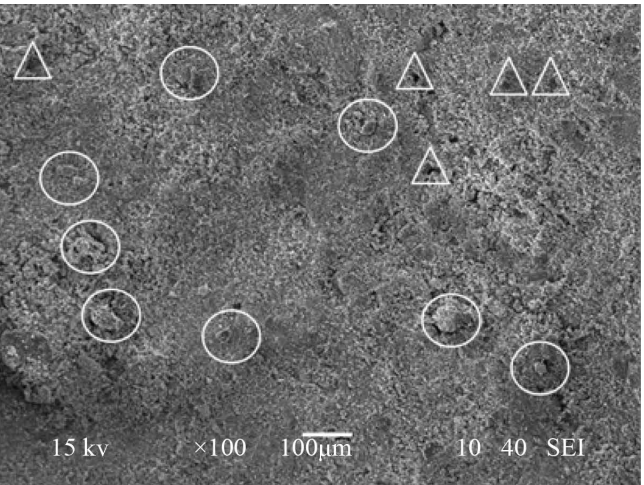

(b)

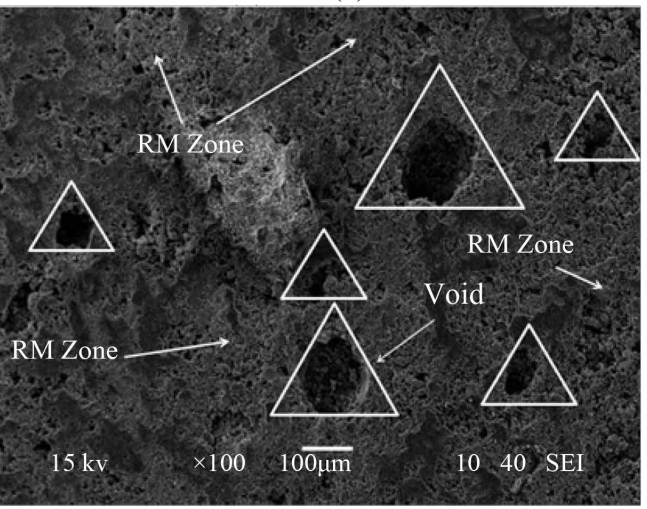

(d)

Figure 6. Microstructure of (a) $10 \%$ RM $+90 \%$ OPSC, (b) $20 \%$ RM $+80 \%$ OPSC, (c) $40 \%$ RM + $60 \%$ OPSC (d) $50 \%$ RM $+50 \%$ OPSC at $\times 100$ magnification. 


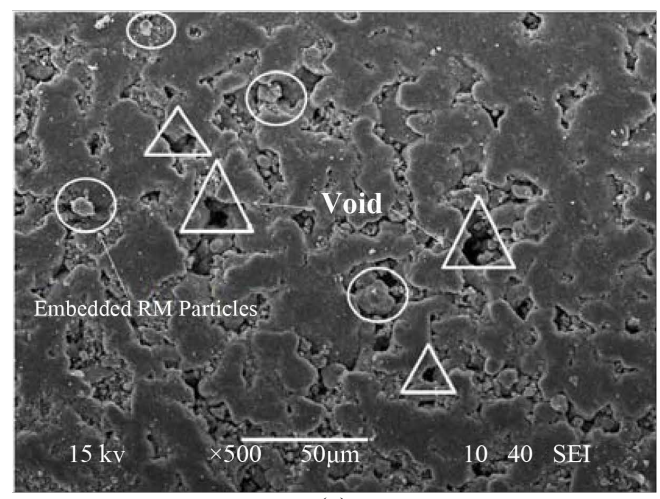

(a)

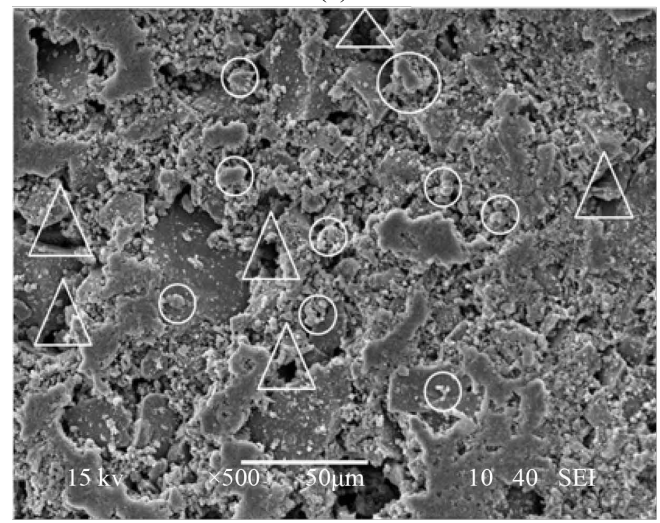

(c)

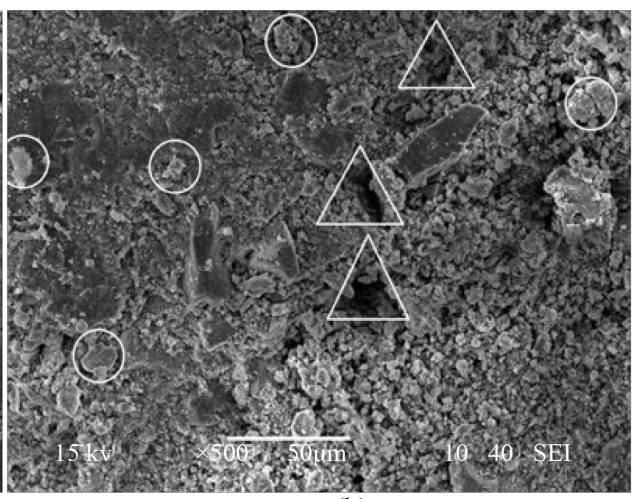

(b)

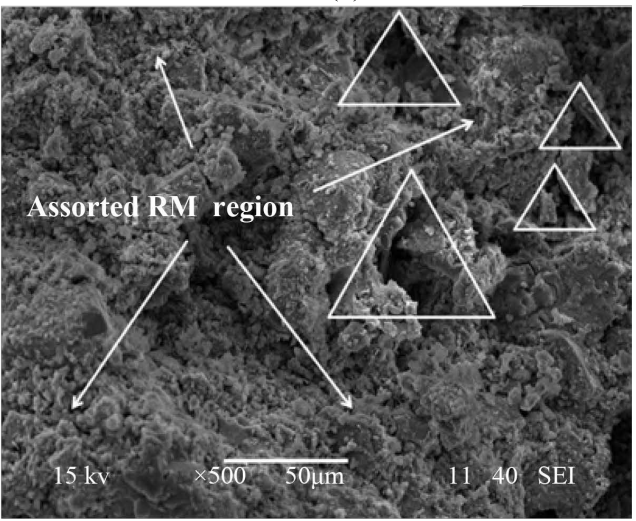

(d)

Figure 7. Microstructure of (a) $10 \% \mathrm{RM}+90 \%$ OPSC, (b) $20 \% \mathrm{RM}+80 \%$ OPSC, (c) $40 \% \mathrm{RM}+$ $60 \%$ OPSC (d) $50 \%$ RM $+50 \%$ OPSC at $\times 500$ magnification.

\section{Conflict of Interest}

All authors declare that no conflict of interest exists for publishing this research paper.

\section{References}

[1] Mendes, A., Sanjayan, J. and Collins, F. (2008) Phase Transformations and Mechanical Strength of OPC/Slag Pastes Submitted to High Temperatures. Materials and Structures, 41, 345-350. http://dx.doi.org/10.1617/s11527-007-9247-8

[2] (2002) A Guide to the Use of Slag in Roads. Australasian Slag Association Inc., Wollongong, 19-21

[3] Mendes, A., Gates, W., Sanjayan, J. and Collins, F. (2011) NMR, XRD, IR and Synchrotron NEXAFS Spectroscopic Studies of OPC and OPC/Slag Cement Paste Hydrates. Materials and Structures, 44, 1773-1791. http://dx.doi.org/10.1617/s11527-011-9737-6

[4] Odler, I. (1998) Lea's Chemistry of Cement and Concrete. 4th Edition, Elsevier, Oxford.

[5] Taylor, H.F.W. (1997) Cement Chemistry. Redwood Books, Wiltshire. http://dx.doi.org/10.1680/cc.25929

[6] Mendes, A., Sanjayan J. and Collins, F. (2009) Long-Term Progressive Deterioration Following Fire Exposure of OPC versus Slag Blended Cement Pastes. Materials and Structures, 42, 95-101. http://dx.doi.org/10.1617/s11527-008-9369-7

[7] Abdel Rahman, A., Abo-El-Enein, S.A., Aboul-Fetouh, M. and Shehata, Kh. (2011) Characteristics of Portland BlastFurnace Slag Cement Containing Cement Kiln Dust and Active Silica. Arabian Journal of Chemistry, In Press, Corrected Proof Research Article. http://dx.doi.org/10.1016/j.arabjc.2011.02.029

[8] Nataraja, M.C. and Nalanda, Y. (2008) Performance of Industrial by Products in Controlled Low-Strength Materials (CLSM). Waste Management, 28, 1168-1181. http://dx.doi.org/10.1016/j.wasman.2007.03.030

[9] Daimon, M. (1980) Mechanism and Kinetics of Slag Cement Hydration. Proceedings of 7th International Congress of Chemistry of Cement, Paris, Vol. I, 2-8.

[10] Lee, T.-C., Wang, W.-J., Shih, P.-Y. and Lin, K.-L. (2009) Enhancement in Early Strengths of Slag-Cement Mortars 
by Adjusting Basicity of the Slag Prepared from Fly-Ash of MSWI. Cement and Concrete Research, 39, 651-658. http://dx.doi.org/10.1016/j.cemconres.2009.02.005

[11] Sutar, H., Mishra, S.C., Sahoo, S.K., Chakraverty, A.P. and Maharana, H.S. (2014) Progress of Red Mud Utilization: An Overview. American Chemical Science Journal, 4, 255-279. http://dx.doi.org/10.9734/ACSJ/2014/7258

[12] Satapathy, A., Sutar, H., Mishra, S.C. and Sahoo, S.K. (2013) Characterization of Plasma Sprayed Pure Red Mud Coatings: An Analysis. American Chemical Science Journal, 3, 151-163. http://dx.doi.org/10.9734/ACSJ/2013/3218

[13] Trezza, M.A. (2007) Hydration Study of Ordinary Portland Cement in the Presence of Zn Ions. Materials Research, 10, 331-334. http://dx.doi.org/10.1590/S1516-14392007000400002

\section{Submit or recommend next manuscript to SCIRP and we will provide best service for you:}

Accepting pre-submission inquiries through Email, Facebook, LinkedIn, Twitter, etc.

A wide selection of journals (inclusive of 9 subjects, more than 200 journals)

Providing 24-hour high-quality service

User-friendly online submission system

Fair and swift peer-review system

Efficient typesetting and proofreading procedure

Display of the result of downloads and visits, as well as the number of cited articles

Maximum dissemination of your research work

Submit your manuscript at: http://papersubmission.scirp.org/ 